\title{
A Rasch analysis of the self-administered Foot Health Assessment Instrument (S- FHAl)
}

Minna Stolt ${ }^{1 *}$, Anders Kottorp ${ }^{2}$ and Riitta Suhonen ${ }^{1,3}$

\begin{abstract}
Background: Reliable and valid measurement is the foundation of evidence-based practice. The self-administered Foot Health Assessment Instrument (S-FHAl) was recently developed to measure patients' evaluations of their own foot health. Evidence regarding the psychometric properties of the S-FHAl is limited. The aim of this study was to investigate those properties by using a Rasch analysis.

Methods: This methodological study analysed secondary data that was collected from nurses $(n=411)$ in 2015 . The psychometric properties of the S-FHAl were evaluated using the Rasch model. Unidimensionality was analysed first, followed by item functioning, person misfit and differential item functioning (DIF).

Results: The S-FHAl demonstrated evidence of unidimensionality, with an acceptable item fit according to the Rasch model. Person fit and person separation were low, however, indicating restricted separation among different respondents. Item separation was high, demonstrating clear discrimination between the items. No DIF was detected in relation to gender, but significant DIF was demonstrated in relation to age for 6 of the 25 items.

Conclusions: The S-FHAl has potential for use in investigating self-reported foot health. The Rasch analysis revealed that the psychometric properties of the instrument were acceptable, although some issues should be addressed to improve the scale. In future, it may be beneficial to analyse the sensitivity of the items and to test the S-FHAl in more diverse patient populations.
\end{abstract}

Keywords: Foot health, Psychometric testing, Rasch analysis, Self-assessment

\section{Background}

Foot health is part of general health. Healthy feet help make pain-free activity possible for people in every age group. This is especially important in occupations that involve long periods of standing or walking, such as nursing. The prevalence of foot problems among nurses is high $[1,2]$. Nurses may experience foot problems that stem from long-term disease (e.g. diabetes, rheumatoid arthritis) or a limited ability in foot self-care, and these issues can affect their ability to work [1-4]. Foot

\footnotetext{
* Correspondence: minna.stolt@utu.fi

${ }^{1}$ Department of Nursing Science, University of Turku, 20014 Turku, Finland Full list of author information is available at the end of the article
}

problems are more prevalent among female and associated with lower quality of life $[5,6]$. The importance of foot health is usually noticed when problems causes pain or discomfort. However, preventative monitoring of foot health is seldom conducted [7]. Therefore, the assessment of foot problems using suitable and reliable instruments is important to identify the problems and promote foot health.

Several instruments are available for measuring foot health. These tools have different aims and perspectives, and they may be designed for either patients or podiatrists to use. Most of the instruments available are related to a specific disease or foot problem; for example,

C C The Author(s). 2021 Open Access This article is licensed under a Creative Commons Attribution 4.0 International License, which permits use, sharing, adaptation, distribution and reproduction in any medium or format, as long as you give appropriate credit to the original author(s) and the source, provide a link to the Creative Commons licence, and indicate if changes were made. The images or other third party material in this article are included in the article's Creative Commons licence, unless indicated otherwise in a credit line to the material. If material is not included in the article's Creative Commons licence and your intended use is not permitted by statutory regulation or exceeds the permitted use, you will need to obtain permission directly from the copyright holder. To view a copy of this licence, visit http://creativecommons.org/licenses/by/4.0/ The Creative Commons Public Domain Dedication waiver (http://creativecommons.org/publicdomain/zero/1.0/) applies to the data made available in this article, unless otherwise stated in a credit line to the data. 
the Manchester Foot Pain and Disability Index [8] measures pain specifically related to a foot disability. Others measure foot-related outcomes on a more general level, such as quality of life related to foot health (e.g. the Foot Health Status Questionnaire) [9] or functional limitation (e.g. the Foot Impact Scale - Dutch version) [10]. The Foot Health Assessment Instrument (FHAI) [11]; is an objective tool used by nurses to measure foot health in older people. Many of the instruments focusing on foot health are administered predominantly by podiatrists, with few considering the patient's perspective. To respond to this need, a self-administered version of the Foot Health Assessment Instrument was developed to measure foot health as reported by patients.

Testing the psychometric properties of foot health instruments is continuous process. Psychometric properties of the instrument should be evaluated every time when the instrument is used in different sample, setting or culture [12]. There are several different language versions of previously validated foot health instruments, for example, the Spanish Bristol Foot Score [13], the Spanish ROWAN Foot Pain Assessment Questionnaire [14] and Turkish version of the Foot Function Index [15]. However, the evaluation of psychometric properties of foot health instruments is largely focused on using classical test theory approach.

The Rasch analysis is a modern test theory approach to assessing the psychometric properties of instruments. It can be used either when developing new instruments or when evaluating and revising existing ones [16]. The Rasch analysis examines the items included in the instrument and the people who are using it. The main assumption in a Rasch analysis is that the probability of responding correctly or incorrectly to a single item is related to both the person's ability and the difficulty of the item [17]. The Rasch analysis provides a wide range of evidence of internal construct validity, such as unidimensionality, category function, item and person separation, and differential item functioning (DIF) [18].

In foot health research, the Rasch analysis has been applied to detect items that are misfits in an instrument and to evaluate its psychometric properties with national and international samples. For example, in the process of developing the Foot Posture Index, the Rasch analysis was used to quantify variation in the position of the foot, detect problematic items and provide evidence of internal construct validity [19]. When the Foot Impact Scale (which measures foot-related impairment and disability) was translated into Dutch, a Rasch analysis was used to evaluate internal construct validity, which led to the deletion of two items [10]. After these deletions, the Foot Impact Scale - Dutch version demonstrated unidimensionality and acceptable goodness-of-fit values [10]. In the context of cross-cultural validation, a Rasch analysis was used to confirm the validity and reliability of the Foot and Ankle Ability Measure [20] and the Manchester Foot Pain and Disability Index - Spanish version [21]. When applied to the American Orthopaedic Foot and Ankle Society Score [22] in a sample of Brazilian patients with rheumatoid arthritis, the Rasch analysis demonstrated one item that did not fit, thus supporting the refinement of the tool.

The development and testing of instruments is an ongoing process. The aim of this study, therefore, was to understand more about the psychometric properties of the S-FHAI by applying a Rasch analysis to secondary data. Five stepwise research questions were set:

(1) What is the rating scale functioning of the S-FHAI?

(2) Do the items in the S-FHAI support a unidimensional underlying construct? In particular:

a. (a) Do the patterns in the participants' responses to the items demonstrate acceptable goodness-of-fit with the Rasch model?

b. (b) Is most of the variance explained by a single underlying construct?

(3) Do the individual responses match the responses expected according to the Rasch model?

(4) Does the S-FHAI separate the sample into a sufficient number of distinct levels of foot health?

(5) Are the item difficulty calibrations stable in relation to gender and age?

The goal was to provide information about the validity and reliability of the S-FHAI and to support its use in clinical practice.

\section{Method}

The methodological design used in this study involved the analysis of secondary data $(n=411)$ from a previously reported study [3]. The data were collected electronically. A random sample was taken from two national associations in Finland: the Finnish Nurses' Association, which represents registered nurses, and the Finnish Union of Practical Nurses, which represents licensed practical nurses. The minimum sample size was estimated with the rule of thumb: $10 \mathrm{x}$ number of items + drop out $=$ sample size [23]: $10 \times 25+50=300$ in this study.

\section{Instrument}

The S-FHAI measures a person's current level of foot health. It consists of 25 items divided into four subcategories: skin health (11 items), nail health (4 items), foot 
structure (5 items) and foot pain (5 items, focusing on intensity and location). The response options in the first three subcategories are dichotomous (yes or no), and in the fourth subcategory (foot pain) a four-point Likert scale (0 to 4 ) is used. The S-FHAI is based on the FHAI [11], which was developed and tested for use by nurses to assess foot health in older people. To improve its use in cross-sectional studies, a self-administered version was constructed [3]. Three items related to the objective assessment of foot sensation and arterial blood supply (palpation of arteria dorsalis pedis and tibialis pulses) were omitted from the S-FHAI. These were replaced with the following five items: blisters, cold feet, muscle cramps, foot sweating and sensation of burning feet). These modifications were discussed and agreed with experts in the fields of podiatry and nursing, and were guided by the previous literature [e.g. 1]. The S-FHAI has been used successfully in Finnish studies measuring nurses' foot health [3, 4]. Both Finnish and English versions of the S-FHAI exist, however this study focus on the Finnish version.

\section{Analysis}

A Rasch partial credit model application was used to assess unidimensionality, item fit, person fit, person separation and item hierarchy. A summary of the steps taken in this approach is provided in Table 1, drawing upon examples from Bonsaksen and colleagues [24] and
Lerdal and colleagues [25]. In this study, the data were analysed using WINSTEPS software (Version 4.4.8) [26].

To determine whether the number of response options was appropriate, the rating scale functioning was examined. This included assessing category frequencies, average measures, infit and outfit mean squares and threshold calibrations. For category frequencies, the minimum requirement is 10 responses per category and the average measures should increase monotonically [33]. If the rating scale demonstrates a low number of category frequencies or disordered average measures, it may be appropriate to combine some of the response categories [33].

Unidimensionality is a main requirement of the Rasch model. For an instrument to be unidimensional, all the items must measure a single construct [17]. Unidimensionality can be assessed by looking at the fit statistics for the items and carrying out a principal components analysis (PCA) of the residuals [34]. Fit statistics are used to identify the items or participants whose responses deviated from what was expected. The fit statistics are normalized mean square residuals and are reported in two ways: infit and outfit statistics. Infit statistics are sensitive to unexpected responses close to an item's measure, and outfit statistics are sensitive to unexpected responses far from an item's measure [17]. In addition, both the infit and outfit statistics have two forms: mean square (MnSq) and standardized mean square (Zstd) [17]. A MnSq value greater than 1.4 or a

Table 1 Rasch approach to analysing the S-FHAl

\begin{tabular}{|c|c|c|c|}
\hline Step & Psychometric property & Statistical approach and criteria & Results (original S-FHAI) \\
\hline 1 & $\begin{array}{l}\text { Rating scale functioning: } \\
\text { Does the rating scale function } \\
\text { consistently across the items? }\end{array}$ & $\begin{array}{l}\text { - Average measures for each category and } \\
\text { threshold on each item should advance } \\
\text { monotonically } \\
\text { - Zstd values }<2.0 \text { in outfit mean square (MnSq) } \\
\text { values for step category calibrations [27] }\end{array}$ & $\begin{array}{l}\text { Four items had less than } 10 \text { responses per } \\
\text { category. Two categories were combined, and } \\
\text { then only two items did not meet the criteria }\end{array}$ \\
\hline 2 & $\begin{array}{l}\text { Internal scale validity: } \\
\text { How closely do the item responses } \\
\text { match the responses expected } \\
\text { according to the Rasch model? }\end{array}$ & $\begin{array}{l}\text { - Item goodness-of-fit values with MnSq values be- } \\
\text { tween } 0.6 \text { and } 1.4 \text { [28] }\end{array}$ & All items met the criterion \\
\hline 3 & $\begin{array}{l}\text { Internal scale validity: } \\
\text { Is the scale unidimensional? }\end{array}$ & $\begin{array}{l}\text { - Principal component analysis, with the first } \\
\text { component explaining } \geq 50 \% \text { of total variance } \\
\text { and any additional component explaining }<5 \% \\
\text { (or eigenvalue }<2.0 \text { ) of the remaining variance }[26]\end{array}$ & $\begin{array}{l}\text { First component explained } 54.2 \% \text { of total } \\
\text { variance, and second component explained } \\
5.9 \% \text { (eigenvalue } 3.25 \text { ) of total variance }\end{array}$ \\
\hline 4 & $\begin{array}{l}\text { Person-response validity: } \\
\text { How closely do the individual } \\
\text { responses match the responses } \\
\text { expected according to the Rasch } \\
\text { model? }\end{array}$ & $\begin{array}{l}\text { - Person goodness-of-fit statistics with infit } \mathrm{MnSq}< \\
1.4 \text { and Zsrd value } \leq 2.0 \text { [29] } \\
\text { • } \leq 5 \% \text { of the sample fails to demonstrate } \\
\text { acceptable goodness-of-fit values [29] }\end{array}$ & $\begin{array}{l}34 \% \text { of participants failed to demonstrate } \\
\text { acceptable goodness-of-fit values }\end{array}$ \\
\hline 5 & $\begin{array}{l}\text { Person-separation reliability: } \\
\text { Can the S-FHAl distinguish between } \\
\text { two distinct foot-health groups in } \\
\text { the sample? }\end{array}$ & - Person-separation index $\geq 2.0$ [30] & 0.37 \\
\hline 6 & $\begin{array}{l}\text { Differential test functioning (DIF): } \\
\text { Are the item difficulty calibrations } \\
\text { stable in relation to gender and age? }\end{array}$ & $\begin{array}{l}\text { - Mantel-Haenszel statistic for polytomous scales } \\
\text { using log-odds estimators in WINSTEPS software } \\
(P<0.01)[31,32]\end{array}$ & $\begin{array}{l}\text { Gender: all item difficulty calibrations were stable } \\
\text { Age: six items had DIF in relation to age }\end{array}$ \\
\hline
\end{tabular}


Zstd value greater than 2.0 indicates a misfit, which means that the item's performance does not match the expectations of the Rasch model. Infit values of less than 0.6 associated with a Zstd value of -2 suggest that an item is not contributing independent information [17, 34-36].

The internal scale validity of the S-FHAI was further examined using a principal component analysis of residuals. For the instrument to demonstrate unidimensionality, the first component should explain more than $50 \%$ of the total variance and any other components should explain less than $5 \%$ of the remaining variance [26]. Person fit provides evidence of person-response validity. This was evaluated by inspecting the person goodnessof-fit values. The criteria were set to $\leq 1.4 \log$-odds units (logits) and an associated Zstd value $<2[37,38]$.

Person reliability and person separation measure how the instrument distinguishes between respondents. The items must be sufficiently separated in terms of difficulty to identify the direction and meaning of the latent scale $[39,40]$. To determine the extent to which the S-FHAI distinguishes among people with different levels of foot health, the separation index was calculated. The separation index criterion was set at $\geq 2.0$, and reliability was set at $\geq 0.80$. Item reliability was calculated in order to examine the degree to which the item response categories reflected increasing levels of difficulty (item separation with the criterion set at $\geq 2.0$ and reliability set at $\geq 0.80$ ). A separation index of 1.5 divides the respondents into two strata (high and low); an index of 2.0 three strata (high, moderate and low); and an index of 3.0 four levels of strata (high, above average, below average and low) [41, 42]. In classical test theory, person separation corresponds to reliability. In the Rasch analysis its meaning is not as pivotal; nevertheless, the index provides some insight into the power of the analysis of fit [41].

The hierarchy of the items determines the order of item difficulty in relation to the distribution of person ability. The Rasch model provides estimates of the item locations (calibrations) that define the order of the items along a measurement continuum [35]. The item calibration provides the hierarchical order of the severity or difficulty of the items on the scale. The Rasch model indicates how well the different items fit into a group of subjects [36]. Item calibration is described in log-odds units (logits), where a greater magnitude represents increasing item difficulty [35, 43]. Ideally, the distribution of the items matches the distribution of the participants $[35,43]$. In this study, the item difficulty was analysed by using an item map and by visually evaluating where the items were located on the continuum.

DIF was used to assess whether or not the item difficulty calibrations were stable in relation to gender (male or female) and age. To analyse the DIF in relation to age, the sample was divided into two groups based on mean age: the age ranged from 19 to 44 in one group and from 45 to 65 in the other. The goal was to provide evidence of the internal structure of the S-FHAI and any potential for unfairness in testing [44].

\section{Ethical considerations}

Good scientific practice [45] was followed throughout the research process. Ethical approval was obtained from the Ethics Committee at the University of Turku (code: $14 / 2015,23.2 .2015$ ) and permission to conduct the study was sought in accordance with national guidelines. All of the participants received information in writing about the purpose of the study, the fact that taking part was voluntary, and the anonymity and confidentiality of the reporting. Written informed consent was obtained from each participant.

\section{Results}

\section{Description of the participants}

In total, responses from 411 nurses were included in the Rasch analysis. The mean age of the participants was 44 years (range 19-65, SD 11.6). Two-thirds of the participants were licensed practical nurses $(n=271,66 \%)$ and the rest were registered nurses $(n=140,34 \%)$. The participants had worked in health care for an average of 14 years (range 0.5-41, SD 10.3).

\section{Rating scale functioning}

The rating scale functioning was assessed to check if the S-FHAI's rating scale was being used as intended. In this dataset, four items $(22,23,24$ and 25) did not reach the target of 10 responses per category. Therefore, to obtain more stable estimates on item difficulty, the categories of 4 (strong pain) and 5 (worst imaginable pain) were combined in items 22-25, which measured incidences of pain in certain areas of the foot. After these modifications had been made, the average measures for each category and the thresholds advanced monotonically, except for two items (pain in the toes and pain in the sole). All the response options in all the items were used.

\section{Item fit}

On the basis of item fit values, the item fit statistics were acceptable for all items and the loading was within the recommended range (Table 2). The item $\mathrm{MnSq}$ ranged from 1.14 to 0.91 , and the Zstd values ranged from 1.33 to -2.68 .

\section{Unidimensionality}

The first component explained $54.2 \%$ of the variance in the data, indicating that the S-FHAI had a satisfactory level of unidimensionality. The largest first contrast 
Table 2 S-FHAl item statistics in order of difficulty (from hardest to easiest)

\begin{tabular}{|c|c|c|c|c|c|c|c|}
\hline & & & & Infit & & Outfit & \\
\hline Item number & Abbreviated item & Measure & SE & $\mathrm{MnSq}$ & Zstd & $\mathrm{MnSq}$ & Zstd \\
\hline 22 & Pain in the toes & 2.01 & 0.07 & 1.14 & 1.17 & 1.93 & 4.47 \\
\hline 25 & Pain in the ankle & 1.72 & 0.06 & 1.06 & 0.70 & 1.33 & 2.67 \\
\hline 23 & Pain in the sole of the foot & 1.69 & 0.06 & 0.98 & -0.20 & 1.14 & 1.22 \\
\hline 6 & Blisters & -2.41 & 0.23 & 1.00 & 0.09 & 1.13 & 0.59 \\
\hline 24 & Pain in the heel & 1.81 & 0.06 & 0.92 & -0.77 & 1.13 & 0.85 \\
\hline 15 & Fungal infection in the nail & -2.95 & 0.30 & 1.02 & 0.15 & 1.12 & 0.48 \\
\hline 20 & High arch & -1.83 & 0.18 & 1.05 & 0.38 & 1.11 & 0.67 \\
\hline 9 & Burning feet & -0.61 & 0.12 & 1.00 & -0.03 & 1.07 & 0.85 \\
\hline 5 & Verruca & -2.08 & 0.20 & 1.00 & 0.04 & 1.06 & 0.35 \\
\hline 21 & Foot pain & 1.41 & 0.11 & 1.05 & 1.33 & 1.04 & 0.86 \\
\hline 16 & Hallux valgus & -0.92 & 0.13 & 1.01 & 0.10 & 1.03 & 0.31 \\
\hline 19 & Low arch & -0.36 & 0.11 & 1.01 & 0.26 & 1.03 & 0.47 \\
\hline 1 & Maceration & 3.04 & 0.17 & 0.99 & -0.03 & 1.02 & 0.20 \\
\hline 10 & Cold feet & 0.62 & 0.10 & 1.01 & 0.46 & 1.02 & 0.75 \\
\hline 7 & Oedema & 0.28 & 0.10 & 0.99 & -0.19 & 1.01 & 0.37 \\
\hline 11 & Muscle cramps & 0.60 & 0.10 & 1.00 & -0.16 & 1.01 & 0.36 \\
\hline 8 & Sweating & 0.50 & 0.10 & 0.98 & -0.68 & 0.98 & -0.71 \\
\hline 17 & Taylor's bunion & -1.40 & 0.16 & 0.98 & -0.14 & 0.93 & -0.53 \\
\hline 18 & Hammer toes & -1.79 & 0.18 & 0.98 & -0.08 & 0.92 & 0.46 \\
\hline 3 & Fissures & 0.41 & 0.10 & 0.96 & -1.51 & 0.95 & -1.55 \\
\hline 12 & Ingrown toenails & -1.36 & 0.15 & 0.96 & -0.29 & 0.94 & -0.43 \\
\hline 2 & Xerosis & 1.98 & 0.12 & 0.94 & -1.01 & 0.87 & -1.66 \\
\hline 4 & Corns or callus & 0.74 & 0.10 & 0.94 & -2.68 & 0.93 & -2.65 \\
\hline 13 & Thickened toenails & -0.30 & 0.11 & 0.91 & -1.77 & 0.88 & -2.11 \\
\hline 13 & Discoloured toenails & -0.80 & 0.13 & 0.91 & -1.14 & 0.86 & -1.60 \\
\hline
\end{tabular}

Infit MnSq mean square standardized residuals; SE standard error; Zstd standardized Z-values

component explained $5.9 \%$ (eigenvalue 3.25 ) of the variance, while the second largest explained $3.3 \%$ (eigenvalue 1.79), which supported internal scale validity.

\section{Person fit}

The majority of the participants had acceptable goodness-of-fit with Rasch model. However, a considerable number were misfits. The goodness-of-fit values from 62 participants $(15 \%)$ were above the criterion of 1.4 , and values from 79 participants (19\%) below the criterion of 0.6 . Therefore, $34 \%$ of people $(n=141)$ did not demonstrate acceptable fit to the Rasch model.

\section{Separation}

The figure for person separation was 0.37 , which indicated that there was a restricted level of separation among the included participants. The figure for item separation was 10.95 , which indicated that the instrument had a good ability to discriminate between and separate the items. The item hierarchy (item map) demonstrates how the items and participants fit together on a continuum. In this study, the participants tended to be located higher than the items. This indicates that the ability of this sample was higher than the ability reflected in the items. The mean of the item measures was less than 1 standard deviation lower than the mean of the person measures, which indicates that the test-item targeting is satisfactory (Fig. 1).

\section{Differential item functioning (DIF)}

The presence of DIF was analysed in relation to gender and age. The analyses revealed that all 25 items in the SFHAI functioned in a similar manner, regardless of gender. However, for age the DIF was significant for six items: fissures, sweating, cold feet, ingrown toenails, thickened toenails and hallux valgus. To check the presence of age-related DIF, the participants were grouped into two new age categories: those under 50 years and those 50 years or over. Even after making this 


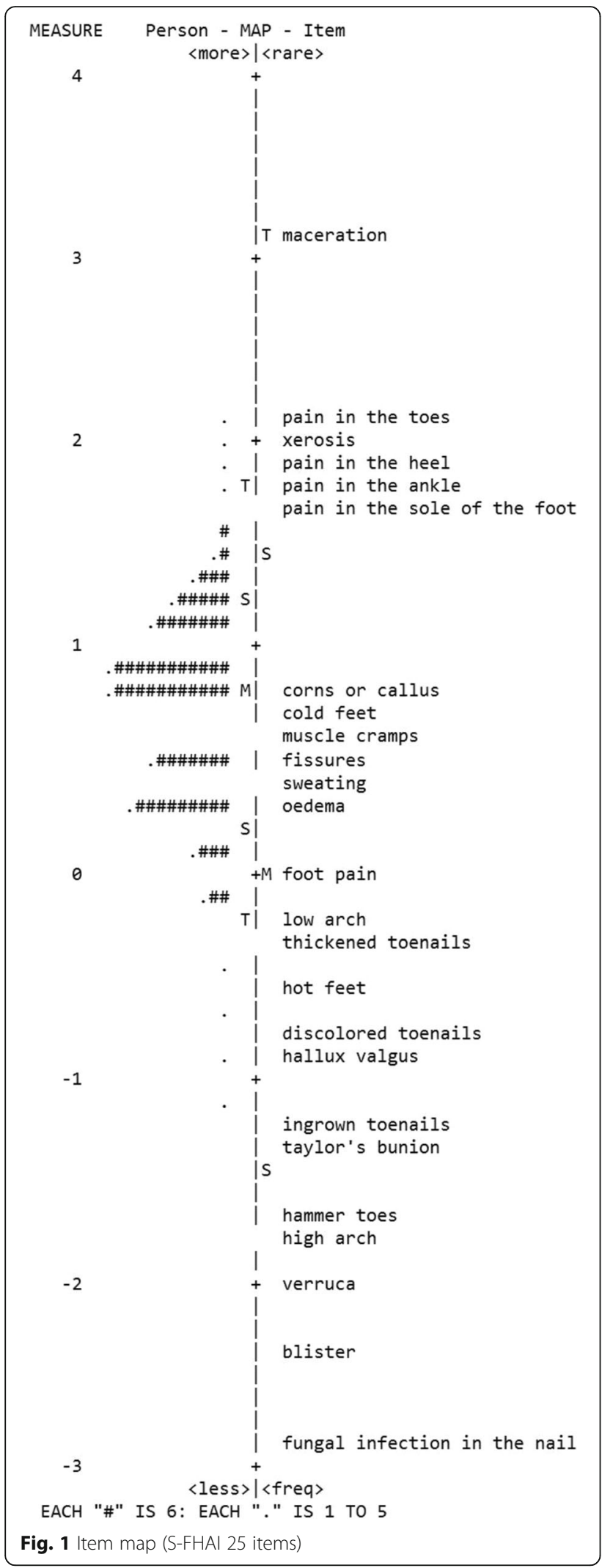

modification, the age-related DIF remained evident in the same six items.

\section{Discussion}

This study evaluated the psychometrics of the S-FHAI from the perspective of item response theory by using a Rasch analysis on responses from a sample of nurses. Mixed findings were demonstrated for the S-FHAI in this cohort. The instrument's internal scale validity was supported in terms of unidimensionality (54.2\%) and all items had an acceptable fit. However, person fit and person separation were poor. In addition, there was significant DIF related to age.

Despite the good internal scale validity in this study, the person-response validity was limited. The percentage of participants demonstrating an unacceptable fit with the Rasch model was higher (34\%) than the criterion $(<$ $5 \%)$. When the goodness-of-fit statistics are higher than expected, this "person misfit" reflects a higher number of unexpected response patterns patterns from the respondents and casts doubt on inferences about a person's score [46]. The S-FHAI was administered by the participants themselves, so it is important to view these findings in relation to the sample. On the basis of the person-item map, where lower scores on single items were not clearly associated with certain items but were more individually distributed, we can assume that the sample's foot health was good or excellent overall,. This may explain the larger proportion of participants with higher goodness-of-fit statistics. A more in-depth analysis of a sample that demonstrated higher goodness-offit statistics could reveal if lower responses on specific items for specific subgroups could explain this pattern. A large proportion of participants with goodness-of-fit statistics that are lower than expected demonstrates "too expected" response patterns, which may be viewed as less of a problem from the perspective of validity.

In future evaluations of the S-FHAI, it will therefore be vital to analyse variables relating to the participants' background when assessing item difficulty. The most difficult items (e.g. nail fungal infections) may be too complicated to identify for participants with a low level of education, as poor knowledge of foot-health issues - or guessing - could affect the responses on this test item. The participants in this study were nursing professionals, so they should have been able to recognize the relevant changes in their feet. However, if their feet were overall healthy, they might not have considered minor foothealth issues or have been able to identify them. Future studies of the S-FHAI in more healthy populations should therefore combine objective outcomes regarding foot health with the subjective perspective gathered with this tool. The objective assessment of foot health may then also potentially explain the unexpected responses 
among individuals resulting in a higher than expected level of misfit.

A low person separation (0.37) was evident in the SFHAI, indicating threats related to sensitivity within this population. It is likely that this low level of separation was caused by the mismatch between the item difficulty and the participants. This may indicate that the S-FHAI can detect people with serious foot problems, but cannot differentiate between those with good or excellent foot health, as might have been the case in this generally "healthy" sample. Nevertheless, the poor separation limits the usefulness of the S-FHAI when it is applied in different populations. Although the findings suggest that the sensitivity of the S-FHAI may be limited when used in more generic and healthy samples, its sensitivity among people whose foot health is poor is still unknown. The S-FHAI is a subjective instrument that can be used to evaluate foot health as reported by patients, so it is important to further analyse whether the items have enough sensitivity to separate people with poorer foot health and also to detect changes over time among these people.

The separation capability of the tool could be improved by implementing several suggestions. First, the number of categories per item ranged from two to five. Therefore, person reliability could be improved by revising the response scale to include more options, such as "no problem", "slight problem" and "severe problem". Second, with only 25 items the S-FHAI is a relatively short scale. Therefore, person separation could be improved by lengthening the scale to include more items, especially the more "challenging" ones. These suggested revisions should be done in accordance with the theoretical framework behind the S-FHAI. Item separation was high (10.95) in this sample and supported the hierarchical way in which the items were organized in the SFHAI [17]. The sample size was large $(n=411)$, which usually results in strong item reliability. It may also require a discussion about the aims of this self-assessment; is it to detect minor issues based on subjective responses in overall healthy samples, or is it to detect those that are in major need of interventions in order to improve foot health? Depending on the aims of the tool, the mismatch between an overall healthy sample and the items can be a serious limitation or not.

DIF was detected in relation to age for six items: fissures, sweating, cold feet, ingrown toenails, thickened toenails and hallux valgus. This is logical, as these foothealth problems are common in an aging population (e.g. $[47,48])$. There was no DIF related to gender. To ensure comparable measures across different respondents, further analysis should be carried out on these six items to identify why the participants responded differently to those items.
The results of this study suggest that it would be beneficial to further revise, adapt and improve the crosscultural validity of the S-FHAI scale, as it possesses some important qualities and has potential for investigating self-reported foot health. On the basis of the Rasch analysis, the psychometric properties of the S-FHAI were acceptable, in spite of some issues that should be addressed. In future, analysing the sensitivity of the items could be of benefit. The S-FHAI should also be tested in more diverse patient populations, especially those including people with lower levels of foot health, as it is more important to detect these from a health intervention perspective. The item hierarchy of the S-FHAI also informs which foot health items are relatively easy to subjectively detect and/or more frequently perceived within a population, to more challenging items that may be harder to detect and/or are less frequently perceived. This information may therefore also inform health professions to specific interventions.

\section{Methodological considerations}

There were limitations in this study. The analysis relied on secondary data, which had been collected from one country. The sample may not be representative when compared with a larger population of nurses. However, the fact that the data were obtained from two national associations is a strength and makes it possible to carry out comprehensive statistical tests. Second, the data collected were the result of self-assessment. Self-assessment has been criticized for producing health-related results that are better than respondents' real health status [49]. Despite this, the evaluations in this sample can be viewed as reasonable, as the participants had received nursing education and were therefore familiar with footrelated issues. The lack of an objective outcome in relation to foot health in this study limits the outcomes to support validity in relation to response processes and internal structure, but not validity evidence in relation to other variables [50]. Finally, the current findings can be generalized to this sample of nurses only and warrant exploration in other populations.

\section{Conclusions}

In conclusion, the S-FHAI showed strong unidimensionality, and the goodness-of-fit values were satisfactory for all the items. The higher proportion of persons demonstrating misfit indicates the need for more detailed information about the foot health characteristics of this overall healthy sample, in order to detect if this a generic validity problem of the tool, or more sample-related. The low separation of the tool also requires further discussions about the aims and target groups for the SFHAI. Future adaptation and cross-cultural validation analyses are needed to test the sensitivity and specificity 
of the S-FHAI in different samples; for example, using receiver operating characteristic curve (ROC) curves in relation to more objective outcomes.

\section{Abbreviations \\ DIF: Differential item functioning.; FHAl: The Foot Health Assessment Instrument.; logits: Log-odds units.; MnSq: Mean square.; PCA: Principal components analysis.; ROC: Receiver operating characteristic curve.; SD: Standard deviation.; SE: Standard error,; S-FHAl: The self-administered Foot Health Assessment Instrument.; Zstd: Standardized mean square.}

\section{Acknowledgements}

None.

\section{Authors' contribution}

MS, AK and RS designed the study. MS collected the data. MS and AK analysed the data. MS drafted the article. AK and RS critically revised the article for important intellectual content. All the authors read and approved the final version of the manuscript

\section{Funding}

Funding for this study was received from the Finnish Work Environment Fund (funding reference 116,464) and Turku University Hospital (funding reference 2017/13,240). These funding bodies were not involved in the study, and they did not play any role in the study design, in the collection, analysis and interpretation of the data, or in writing the manuscript.

\section{Availability of data and materials}

The datasets used and analysed during the current study are available from the corresponding author upon reasonable request.

\section{Declarations}

\section{Ethics approval and consent to participate}

Ethical approval was obtained for this research, and all participants gave their written informed consent to participate. The Ethics Committee at the University of Turku approved the study (code: ETMK 14/2015, 23.2.2015).

\section{Consent for publication}

Not applicable.

\section{Competing interests}

The authors declare that they have no competing interests.

\section{Author details}

'Department of Nursing Science, University of Turku, 20014 Turku, Finland. ${ }^{2}$ Faculty of Health and Society, Malmö University, Malmö, Sweden. ${ }^{3}$ Turku University Hospital and City of Turku Welfare Division, Turku, Finland.

\section{Received: 7 August 2020 Accepted: 4 June 2021}

\section{Published online: 15 June 2021}

\section{References}

1. Reed LF, Battistutta D, Young J, Newman B. Prevalence and risk factors for foot and ankle musculoskeletal disorders experienced by nurses. BMC Musculoskelet Disord. 2014;15:196. doi:https://doi.org/10.1186/1471-2474-1 5-196.

2. Stolt $M$, Suhonen R, Virolainen $P$, Leino-Kilpi H. Lower extremity musculoskeletal disorders in nurses: A narrative literature review. Scand Public Health. 2016:44:106-15.

3. Stolt M, Suhonen R, Kielo E, Katajisto J, Leino-Kilpi H. Foot health of nurses A cross-sectional study. Int J Nurs Pract. 2017. doi:https://doi.org/10.1111/ ijn. 12560.

4. Stolt M, Katajisto J, Suhonen R, Leino-Kilpi H. Development and testing of a new electronic Foot Health Promotion Programme on nurses' foot self-care. BMC Nurs. 2020;19:29. https://doi.org/10.1186/s12912-020-00423-z.

5. López-López D, Becerro-de-Bengoa-Vallejo R, Losa-Iglesias ME, PalomoLópez P, Rodríguez-Sanz D, Brandariz-Pereira JM, Calvo-Lobo C. Evaluation of foot health related quality of life in individuals with foot problems by gender: a cross-sectional comparative analysis study. BMJ Open. 2018;8: e023980. doi:https://doi.org/10.1136/bmjopen-2018-023980.
6. Palomo-López P, López-López D, Becerro-de-Bengoa-Vallejo R, Losa-Iglesias ME, Rodríguez-Sanz D, Fernández-Carnero J, Martiniano J, Calvo-Lobo C. Concurrent Validity of the Foot Health Status Questionnaire and Study Short Form 36 for Measuring the Health-Related Quality of Life in Patients with Foot Problems. Medicina. 2019;55(11):750. doi:https://doi.org/10.3390/ medicina55110750.

7. López-López D, García-Mira R, Palomo-López P, Sánchez-Gómez R, RamosGalván J, Tovaruela-Carrión N, García-Sánchez M. Attitude and knowledge about foot health: a Spanish view. Rev Lat Am Enfermagem. 2017;25:e2855. doi:https://doi.org/10.1590/1518-8345.1643.2855.

8. Garrow AP, Papageorgiou AC, Silman AJ, Thomas E, Jayson MI, Macfarlane GJ. Development and validation of a questionnaire to assess disabling foot pain. Pain. 2000:85:107-13.

9. Bennett PJ, Patterson C, Wearing S, Baglioni T. Development and validation of a questionnaire designed to measure foot-health status. J Am Podiatr Med Assoc. 1998;88:419-28. doi:https://doi.org/10.7547/87507315-88-9-419.

10. Woodburn J, Vliet Vlieland TP, van der Leeden M, Steultjens MP. Rasch analysis of Dutch-translated version of the Foot Impact Scale for rheumatoid arthritis. Rheumatology. 2011:50:1315-19.

11. Stolt $M$, Suhonen $R$, Puukka P, Viitanen M, Voutilainen P, Leino-Kilpi H. Development process and psychometric testing of foot health assessment instrument. J Clin Nurs. 2013;22:1310-21. doi:https://doi.org/10.1111/jocn.12 078.

12. Souza AC, Alexandre NMC, Guirardello EB. Psychometric properties in instruments evaluation of reliability and validity. Epidemiol Serv Saude. 2017; 26(3):649-59. doi:https://doi.org/10.5123/S1679-49742017000300022.

13. Navarro-Flores E, Losa-Iglesias ME, Becerro-de-Bengoa-Vallejo R, Lopez-Lopez D, Vilar-Fernandez JM, Palomo-Lopez P, Calvo-Lobo C. Transcultural Adaptation and Validation of the Spanish Bristol Foot Score (BFS-S). Aging Dis. 2018;9(5):861-8. doi:https://doi.org/10.14336/AD.2017.1215.

14. Navarro-Flores E, Becerro-de-Bengoa-Vallejo R, Losa-Iglesias ME, PalomoLopez P, Lopez-Lopez D, Sanchez-Gomez R, Calvo-Lobo C. Cross-Cultural Adaptation and Test-Retest Reliability of the Spanish ROWAN Foot Pain Assessment Questionnaire (ROFPAQ-S). Pain Physician. 2020:23(1):E1-6.

15. Anaforoğlu Külünkoğlu B, Fırat N, Yıldız NT, Alkan A. Reliability and validity of the Turkish version of the Foot Function Index in patients with foot disorders. Turk J Med Sci. 2018;48(3):476-83. doi:https://doi.org/10.3906/sa g-1705-143.

16. Bortolotti SLV, Tezza R, de Andrade DF, Bornia AC, de Sousa Jr. AF. Relevance and advantages of using the item response theory. Qual Quant. 2013;47:2341-60. https://doi.org/10.1007/s11135-012-9684-5.

17. Bond TG, Fox CM. Applying the Rash model: fundamental measurement in the human sciences. 3rd edition. New York, NY: Routledge; 2015.

18. Tennant A, Conaghan PG. The Rasch measurement model in rheumatology: what is it and why use it? When should it be applied, and what should one look for in a Rasch paper? Arthritis Rheum. 2007;57:1358-62. doi:https://doi. org/10.1002/art.23108.

19. Keenan A-M, Redmond AC, Horton M, Conaghan PG, Tennant A. The Foot Posture Index: Rasch Analysis of a Novel, Foot-Specific Outcome Measure. Arch Phys Med Rehabil. 2007;88:88-93.

20. Moreira TS, Magalhaes LC, Silva RD, Martin RL, Resende MA. Translation, cross-cultural adaptation and validity of the Brazilian version of the Foot and Ankle Ability Measure questionnaire. Disabil Rehabil. 2016:38:2479-90.

21. Gijon-Nogueron G, Ndosi M, Lugue-Suarez A, Alcacer-Pitarch B, Munuera PV, Garrow A, Redmond AC. Cross-cultural adaptation and validation of the Manchester Foot Pain and Disability Index into Spanish. Qual Life Res. 2014; 23:571-79.

22. Conceicao CS, Gomes Neto M, Costa Neto A, Mendes SM, Baptista AF, Sa $\mathrm{KN}$. Analysis of the psychometric properties of the American Orthopaedic Foot and Ankle Society Score (AOFAS) in rheumatoid arthritis patients: application of the Rasch model. Rev Bras Reumatol Engl Ed. 2016;56:8-13.

23. Hair JF Jr, Black WC, Babin BJ, Anderson RE. Multivariate Data Analysis. 7th ed. Essex: Pearson Education Limited; 2011.

24. Bonsaksen T, Kottorp A, Gay C, Fagermoen MS, Lerdal A. Rasch analysis of the General Self-Efficacy Scale in a sample of persons with morbid obesity. Health Qual Life Outcomes. 2013;11:202. http://www.halo.com/ content/11/1/202

25. Lerdal A, Kottorp A Gay C, Aouizerat BE, Lee KA, Miaskowski C. A Rasch Analysis of Assessments of Morning and Evening Fatigue in Oncology Patients Using the Lee Fatigue Scale. J Pain Symptom Manage. 2016;51: 1002-12. doi:https://doi.org/10.1016/j.jpainsymman.2015.12.331. 
26. Linacre J. A user's guide to Winsteps. Chicago: MESA Press; 2011.

27. Linacre JM. Optimizing rating scale category effectiveness. In: Smith EV, Smith RM, editors. Introduction to Rasch measurement: Theory, models and applications. Maple Grove: JAM Press Publisher; 2004

28. Wright BD, Linacre JM. Reasonable meansquare fit values. Rasch Measurement Transactions. 1994:8:370.

29. Kottorp A, Bernspang B, Fisher AG. Validity of a performance assessment of activities of daily living for people with developmental disabilities. J Intellect Disabil Res. 2003;47:605. doi:https://doi.org/10.1046/j.1365-2788.2003.00475.x.

30. Fisher W. Reliability statistics. Rasch Measurement Transactions. 1992;6:238.

31. Mantel N. Chi-square tests with one degree of freedom; extensions of the Mantel-Haenszel procedure. J Am Stat Assoc. 1963;58:690-700.

32. Mantel N, Haenszel W. Statistical aspects of the analysis of data from retrospective studies of disease. J Natl Cancer Inst. 1959:22:719-48.

33. Linacre JM. Optimizing rating scale category effectiveness. J Appl Meas. 2002:3:85-106.

34. Smith EV Jr. Detecting and evaluating the impact of multidimensionality using item fit statistics and principal component analysis of residuals. J Appl Meas. 2002;3:205-31.

35. Prieto L, Alonso J, Lamarca R. Classical test theory versus Rasch analysis for quality of life questionnaire reduction. Health Qual Life Outcomes. 2003a:1: 27. doi: https://doi.org/10.1186/1477-7525-1-27.

36. Smith AB, Fallowfield LJ, Stark DP, Velikova G, Jenkins V. A Rasch and confirmatory factor analysis of the general health questionnaire (GHQ)-12. Health Qual Life Outcomes. 2010;30:45. doi:https://doi.org/10.1186/1477-752 5-8-45.

37. Nilsson I, Fisher AG. Evaluating leisure activities in the oldest old. Scand J Occup Ther. 2006;13:31-7.

38. Patomella AH, Tham K, Kottorp A. P-drive: assessment of driving performance after stroke. J Rehabil Med. 2006;38:273-79.

39. Forkmann T, Boecker M, Wirtz M, Glaesmer H, Brahler E, Norra C, Gauggel S. Validation of the Rasch-based Depression Screening in a large scale German general population sample. Health Qual Life Outcomes. 2010;8:105. doi: https://doi.org/10.1186/1477-7525-8-105.

40. Wright BD, Stone MH. Five steps to science: Observing, scoring, measuring analyzing, and applying. Rasch Measurement Transactions. 2003;17:912-3.

41. Pallant JF, Tennant A. An introduction to the Rasch measurement model: an example using the Hospital Anxiety and Depression Scale (HADS). Br J Clin Psychol. 2007;46:1-17.

42. Ross KB, Doyle PJ. Measuring change using communication rating scales: The case for Rasch analysis, as illustrated with the ASHA FACS. J Med Speech Lang Pathol. 2008:16;ix - xii.

43. Prieto L, Novick D, Sacristán JA, Edgell ET, Alonso J, on the behalf of the SOHO Study Group. A Rasch model analysis to test the cross-cultural validity of the EuroQoL-5D in the Schizophrenia Outpatient Health Outcomes Study. Acta Psychiatr Scand Suppl. 2003b;(416):24-9. doi:https://doi.org/10.1 034/j.1600-0447.107.s416.6.x.

44. Rouquette A, Hardouin J-B, Vanhaesebrouck A, Sébille V, Coste J. Differential Item Functioning (DIF) in composite health measurement scale: Recommendations for characterizing DIF with meaningful consequences within the Rasch model framework. PLoS ONE. 2019;14:e0215073. doi: https://doi.org/10.1186/1471-2474-15-196

45. Allea. The European Code of Conduct for Research Integrity. 2017. https://a llea.org/code-of-conduct/. Accessed 7 Apr 2020.

46. Walker AA, Jennings JK, Engelhard $G$ Jr. Using person response functions to investigate areas of person misfit related to item characteristics. Educational Assessment, 2018;2347 - 68, DOl: https://doi.org/10.1080/10627197.2017.141 5143.

47. Hendry GJ, Fenocchi L, Woodburn J, Steultjens M. Foot pain and foot health in an educated population of adults: results from the Glasgow Caledonian University Alumni Foot Health Survey. J Foot Ankle Res. 2018;11:48. doi: https://doi.org/10.1186/s13047-018-0290-1.

48. Stolt M, Suhonen R, Voutilainen $\mathrm{P}$, Leino-Kilpi H. Foot health in older people and the nurses' role in foot health care-a review of literature. Scand J Caring Sci. 2010;24:194-201. doi:https://doi.org/10.1111/j.1471-6712.2009.00700.x.

49. Hébert R, Raiche M, Gueye NR. Survey disability questionnaire does not generate valid accurate data compared to clinical assessment on an older population. Arch Gerontol Geriatr. 2008;54:e57-62. https://doi.org/10.1016/j.a rchger.2011.06.021.
50. American Educational Research Association. The Standards for Educational and Psychological Testing. American Educational Research Association: Washington D.C.; 2014

\section{Publisher's Note}

Springer Nature remains neutral with regard to jurisdictional claims in published maps and institutional affiliations.
Ready to submit your research? Choose BMC and benefit from:

- fast, convenient online submission

- thorough peer review by experienced researchers in your field

- rapid publication on acceptance

- support for research data, including large and complex data types

- gold Open Access which fosters wider collaboration and increased citations

- maximum visibility for your research: over $100 \mathrm{M}$ website views per year

At BMC, research is always in progress.

Learn more biomedcentral.com/submissions 